\title{
International Journal of Economics and Finance
}

www.ccsenet.org/journal.html

Vol. 1, No. 1

February 2009

\section{Cognitive Pattern Analysis Employing Neural Networks:}

\section{Evidence from the Australian Capital Markets}

\author{
Edward Sek Khin Wong \\ Faculty of Business \& Accountancy \\ University of Malaya \\ 50603, Kuala Lumpur, Malaysia \\ E-mail: edwardwong@graduate.uwa.edu.au
}

\begin{abstract}
An artificial neural network is an intelligent system using computers that allows users to improve performance through pattern recognition. Neural networks benchmark their predictions with actual results and constantly revise their predictions, improving forecasting capability. The purpose of this paper is to support the use of neural networks as a detection mechanism tool to discover market inefficiencies in financial markets. Using the Australian capital market as an example, this study investigates the question of the existence of market inefficiencies using artificial neural networks as the investigative tool. This study also focuses on whether additional publicly sourced information when used as input through a neural network, can provide investors with a trading advantage over traditional financial models. In finance, any forecasting advantage obtained through the use of publicly available information even if internal, external or both indicate some form of inefficiency in the financial markets. In this paper, we explore the efficiency of the four capital markets, the United States, Japan, Hong Kong and Australia, but focusing on the Australian capital market using the Australian Stock Exchange's 200 (ASX 200) index. Our research demonstrates how the inclusion of external information to our neural network model can provide a significant trading advantage. Although our preliminary analysis suggests the Australian market is as efficient as the US market, other results suggest the Australian market may be less efficient, when we take into account of external information from other financial markets. Our results show that accounting for external market signals can significantly improve forecasts on the ASX200 index but show little benefit on forecasts for the Dow Jones Industrial Average (DJIA) index. Using external market signals, our neural network model's prediction accuracy of the ASX200 index increases by an additional 10 percent from 50 to 60 percent accuracy. This suggests the inclusion of publicly available external signals can significantly improve neural network forecasts. By exploiting this additional information, this method can improve returns for investors who incorporate such signals in their neural network models.
\end{abstract}

Keywords: Neural networks, Cognitive engineering, Intelligence systems, Australian capital market, Market inefficiency

\section{Introduction}

In finance literature, the issue of capital market efficiency is a most important topic and factor for decision making. Any ability by any investor to improve their returns by exploiting publicly available information constitutes market inefficiency (Walczak 1999). In an efficient market, information when released to the markets, are also assumed to be priced into the capital market, as they react to the new knowledge and adjust their value instantaneously to reflect their "true" values. Hence, there is no trading advantage, when publicly available information is used to trade. (Note 1). Since publicly available information is expected to be quickly reflected in financial markets when it is released, one would expect the more established capital markets, such as New York Stock Exchange (Dow Jones Industrial Average, DJIA) and Tokyo Stock Exchange (Nikkei 225 average) to be close to efficiency due to the fluidity of these markets. The ability to forecast movements in these market using publicly available external signals would be inconsistent to market efficiency. For the purposes of this paper, an efficient market is defined as a market that is random and unpredictable, and inefficiency is any variation from this definition. According to Levich (1981), 50 percent prediction accuracy is reasonable, when compared against human trading performance in the capital markets. This suggests any model that can predict future values with accuracy greater than 50 percent violates this concept of an efficient market.

\subsection{Research Objectives}

The purpose of this paper is to test the proposition of whether market inefficiencies exist in the Australian market using neural networks. As neural networks are capable of predicting future values of data, neural networks can simultaneously 
test market inefficiencies and evaluate these to show the trader if there is any trading advantage using these inefficiencies for trading advantages. This study also investigates whether the inclusion of additional external market indicators such as information from other markets can improve forecasts of the Australian market

\section{Literature Review}

\subsection{Australian Stock Exchange}

The Australian stock exchange is one of the largest exchanges with the largest volumes of daily trades in southern hemisphere. Despite its relative size, several factors are known to influence movements on the Australian stock exchange. Yoda (1994) finds the Australian markets are influenced by changes in anticipated production levels and interest rates of more established markets such as the United States (US), Europe, and Japan, with the U.S. commanding the highest influence.

Besides the influence anticipated foreign production levels, other factors also influence the Australian market. A study by McGee (1997) finds a strong correlation among these established markets when the global economy world faced the Asia Crisis around the October 1997 crashed. Another study by Kwok (1995) also finds movements in these markets such as the US, Hong Kong, London, and Japan influences movements in the Australian financial market. The co-integration between these markets shows some nonlinear dependencies of daily stock returns for periods lasting one to five days (Yadav, 1996). This suggests neural networks may be appropriate for predicting market performance of periods lasting one to five days.

\subsection{Neural Networks in Market Forecasting}

Neural Networks mimics the human brain's ability to classify patterns or to make predictions or decisions based upon past experience using data sets (Specht, D. and Shapiro, P, 1991). This enables us to build sophisticated custom problem solving applications without programming (Burrascano 1991).

Past studies have used neural networks to forecast individual stock market indices. Due to the popularity of neural networks, there is an overabundance of studies using neural networks in financial market research. Most of these studies focus on predicting established markets such as the US, London, Hong Kong, and the Japan markets (Bosarge, 1993, Yoda, 1994 and Tsibouris and Zeidenberg, 1995). Although many studies have been done on these markets, most past studies continue to focus on using only internal market information. This includes moving averages, trading volume, and interest rates of the particular market for predicting future values. According to Bosarge (1993) and Yoda (1994), these studies have a typical performance rate of 50 to 53 percent accuracy. We believe by accounting for additional external information produced by markets which are co-integrated with the Australian market, our model can improve forecasts. For the purpose of this study, the 50 percent prediction accuracy is assumed to typical neural network capability, or random based behaviour.

\section{Data and Methodology}

In this study, the data is sourced from DataStream International where the closing values of the market index of four countries; the ASX200, DJIA (Dow Jones Industrial Average), Nikkei 225, and Hang Seng index are selected. Data for each index is sourced between the periods of Jan 3, 2006 through October 16, one-day, two-day, and five-day simple returns for each index are calculated. Figure 1 shows the ASX200 index value for the entire period.

\section{Insert Figure1 Here}

Other input variables over this period are also added as inputs into our neural network. These include simple averages and trade volume for each financial market, which has been consistently used in past studies.

\subsection{Development of Model}

From the literature review, it is well established that the presence of inefficient behaviour exist in financial markets. (Note 2). This is particularly highlighted in Lo and MacKinlay (1988) using a variance ratio test. (Note 3) However, in this study we only focus on the performance of our neural network in predicting the index values of the four financial markets; (1) ASX200, (2) DJIA, (3) Nikkei 225, and (4) Hang Seng. For each of the four markets, our neural network is conditioned to predict the five-day future value of each index for each respective market. An example of a neural network using the ASX 200 is shown below in Figure 2.

Insert Figure 2 Here

\section{Insert Figure 3 Here}

In this study, we use a neural network with one hidden layer back propagation network for each input variable set. For this type of neural network, the decision nodes for each market are developed in three main stages. The first stage involves feeding inputs into the model to develop its predictive capability through the pattern recognition by its nodes (January 3, 2005 to December 30, 2005). The second stage is often known as the training stage January 3, 2006 to June $30,2006)$ and involves creating a back-propagative or feedback function into the neural network algorithm. In this stage, 
the available data of the model is tested by predicting future values and these predicted values are not produced as output to the user, instead this data allows the algorithm to adjust for predictive errors encountered, increasing its accuracy in predicting future market index values. In the backward-propagation stage, the training data is vital as it improves the predictive capability by accounting for errors in the network's predictive process. In the final stage (July 3 , 2006 to October 15, 2006), from which our research results are based, is the process of simply predicting future five day values that are not in the earlier two stages.

For each financial market the inputs of one-day, two-day, and five-day lags of closing index values, along with the corresponding one-day, two-day, and five-day average trading volumes are calculated for respective markets.

The predictive capability of our neural network is also evaluated in two stages, with both using the nonparametric runs test. This test is specifically chosen as it compares the frequency of a run (two consecutive periods of financial data moving in the same direction) against the frequency of instances where they do not move in the same direction. This test basically suggests the data tested should be random and hence approximately half (50\%) of the observations should occur in runs and half that do not (Urrutia 1995). This statistic is calculated by multiplying the value of $1-M A E$ (Mean Absolute Error) by 100, where the error is 0 if the correct direction of change is predicted and 1 if not so predicted. For each market, the null hypothesis of 50 percent prediction accuracy is assumed based on the review of past studies. The $p$ value indicates the confidence of rejecting the null hypothesis of $50 \%$.

In the first stage, our neural network model's ability is evaluated using only internal data for each financial market. The second stage focuses upon investigating if adding external data from other markets as inputs can improve our model's predictive capability.

\section{Results}

Stage One:

\section{Insert Table 1 Here}

From Table 1, we can see at a 0.10 confidence level, it is sufficient to reject our hypothesis for both the ASX200 and Hang Seng market index. At the higher 0.05 confidence level, the null hypothesis can only be rejected for ASX200 market index. This suggests that there may be some inefficiency to indicate the presence of non-random market behaviour and this factor can provide a significant trading advantage to investors. Having identified the potential for the Australian market to be inefficient, we next focus on evaluating whether the use of information from different markets effects can improve our forecasts.

\section{Stage Two:}

Focusing only on the Australian market, six different sets of variables are implemented in our neural network model to investigate if the inclusion of external signals has an effect in the apparently inefficient markets of Australia. The various combinations of external impacts are used to determine the effect of specific signals to the Australia markets. Prediction accuracy results for the single hidden layer networks are displayed in Table 2.

Insert Table 2 Here.

From our results in Table 2, we find that when additional external signals, publicly available information, are taken into account, our nonlinear neural network model predictive performance improves from $49.71 \%$ to $59.57 \%$. Our result suggests that external publicly available signals when used as inputs can be used to predict the market more reliably; this indicates some inefficiency in the Australia market.

\section{Conclusion}

Neural networks provide a tool for evaluating the presence of an inefficient market and exploiting that inefficiency. In this study, it is shown that neural networks can evaluate inefficiencies in the Australian capital market. It is also able to predict future values of the market quite reliably.

Our results show the Australian capital market appears the most inefficient market against the other three markets the Hang Seng, Nikkei 225, and DJIA. This suggests there may be hidden investment rules that allow traders to "beat the market" make positive abnormal profits on the Australia stock market.

Although our results indicate some form of inefficiency in the Australian market, it must be noted that our results are limited to using a simple neural network as a predictive model. The neural network used had only one hidden layer back propagation network for each input variable set. The use of a single hidden layer back propagation was assumed to be sufficient to validate the nonlinear function.

Although our approach is geared towards the results of past studies, the development of neural networks in providing an intelligent decision aid for determining the relative efficiency in Australia market is shown. Further work may be conducted by re-investigating our results using a more complex layer or identifying the optimal neural network architecture for use in forecasting, to show if trading advantages do exist in other equity markets. Neural networks as a 
tool can aid investors in identifying investment strategies to capitalise on any potential market inefficiencies.

\section{References}

Bosarge, W. E. (1993). Adaptive Processes to Exploit the Nonlinear Structure of Financial Market.

In: R. R. Trippi \& E. Turban (eds.). Neural Networks in Finance and Investing. Probus Publishing, pp. 371--402.

Burrascano, P. (1991). Learning Vector Quantization for the Probabilistic Neural Network. Proceedings of the IEEE International Conference on Neural Networks, July 1991, Vol. 2, pp. 458-461.

Kwok, R.H.F. (1995). Market Integration in the Four Newly Industrialised Economies of Asia, Advances in Pacific Basin Financial Markets, Vol. 1, pp. 199-209.

Levich, R. \& L.R. Thomas. (1993). The Significance of Technical Trading-Rule Profits in the Foreign Exchange Market: A Bootstrap Approach, Journal of International Money and Finance, Vol12, pp. 451-474.

Lo, A. W. \& MacKinlay, A. C. (1988). Stock Market Prices Do Not Follow Random Walks: Evidence from a Simple Specification Test, Review of Financial Studies Vol.1, pp. 41-66.

Specht, D. and Shapiro, P. (1991). Generalization Accuracy of Probabilistic Neural Networks Compared with BackPropagation Networks. Proceedings of the International Joint Conference on Neural Networks, July 8-1, 1991, Vol 1, pp. 887-892.

Steven Walczak. (1999). Quality of Neural Network Financial Models as a Function of Time. Decision Sciences Institute 5th International Conference Proceedings, pp. 537-539.

Steven Walczak. (2001). An Empirical Analysis of Data Requirements for Financial Forecasting with Neural Networks. Journal of Management Information Systems, 17 (4), 203-222.

Tsibouris, G. and Zeidenberg, M. (1995). Testing the efficient markets hypothesis with gradient descent algorithms. In A.P. Refenes, editor, Neural Networks in the Capital Markets, chapter 8, pages 127--136. John Wiley \& Sons, Chichester, England, 1995.

Urrutia, J.L. (1995). Tests of random walk and market efficiency for Latin American emerging equity markets. Journal of Financial Research, 18, 3 (Fall 1995), pp. 299-309.

Yadav, P.K.; Paudyal, K.; and Pope P.F. (1996). Non-linear Dependence in Daily Stock Returns: Evidence from Pacific Basin Markets - Advances in Pacific Basin Financial Markets, Vol 2 Part B (1996) pp 349-377.

Yoda, M. (1994). Predicting the Tokyo stock market. In G.J. Deboeck (ed.), Trading on the Edge: Neural, Genetic, and Fuzzy Systems for Chaotic Financial Markets. New York: Wiley, 1994, pp. 66-79.

\section{Notes}

Note 1. In finance, this is commonly known as semi-strong form efficiency of financial markets.

Note 2. See Bosarge 1993, Yoda 1994 and Tsibouris and Zeidenberg 1995 for some evidence.

Note 3. The variance ratio test is also performed in the markets by the author, but not reported. For these results please contact the author.

Table 1. Single Intramarket index set Neural Network Model

\begin{tabular}{|l|l|l|}
\hline Index & $\begin{array}{l}\text { Nonparametric Runs } \\
\text { Prediction accuracy }\end{array}$ & $P$ value (confidence level) \\
\hline ASX200 & 49.81 & $0.082^{* *}$ \\
\hline & & \\
\hline DJIA & 56.87 & 0.069 \\
\hline & & \\
\hline Nikkei & 47.29 & 0.956 \\
\hline & & \\
\hline Hang Seng & 54.97 & $0.102^{*}$ \\
\hline & & \\
\hline
\end{tabular}

* indicates significant at the 0.10 level

** indicates significant at the 0.05 level 
Table 2. Neural Networks to Predict ASX200 Five-day Futures.

\begin{tabular}{|l|l|l|}
\hline Indexes & Prediction accuracy & P value \\
\hline ASX200 & 49.81 & 0.082 \\
\hline ASX200 and Hang Seng & 51.79 & $0.366^{* *}$ \\
\hline ASX200 and Nikkei & 52.59 & $0.219^{* *}$ \\
\hline ASX200 and DJIA & 54.27 & $0.1841^{* *}$ \\
\hline ASX200, Hang Seng, Nikkei and DJIA & 59.57 & $0.003^{* *}$ \\
\hline
\end{tabular}

** indicates significant at the 0.05 level

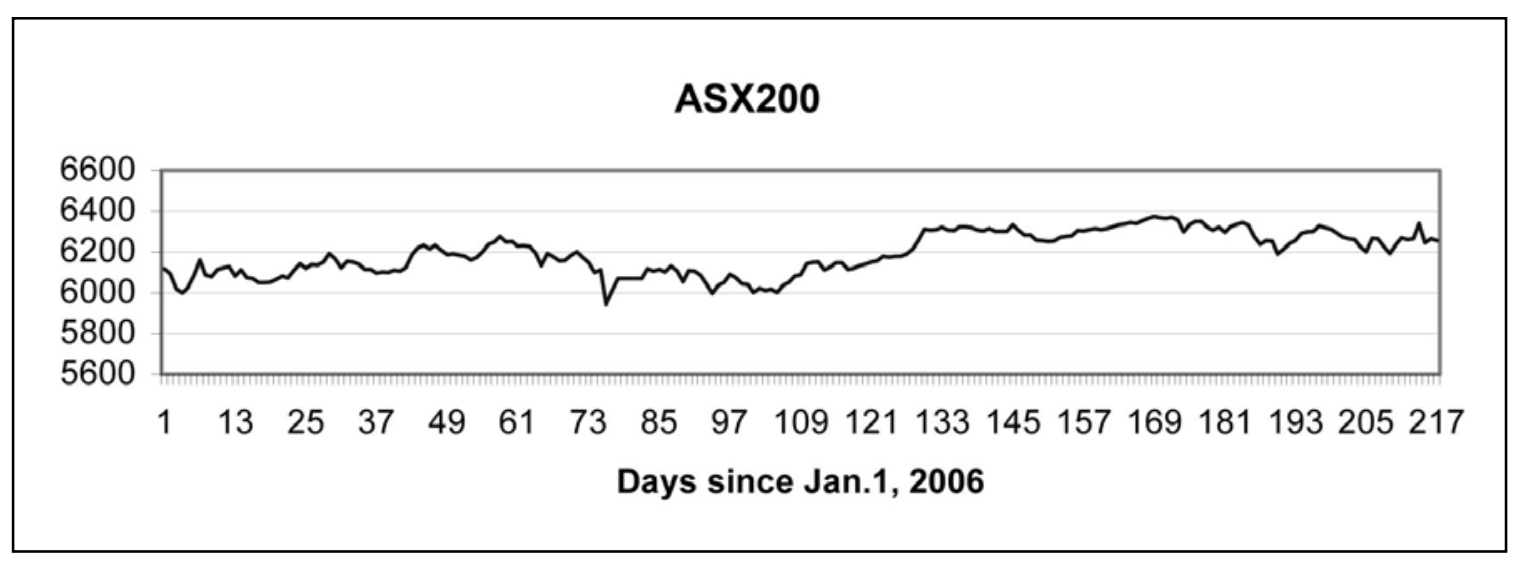

Figure 1. ASX200 Market Index Values, January 3, 2006 - October 16, 2006

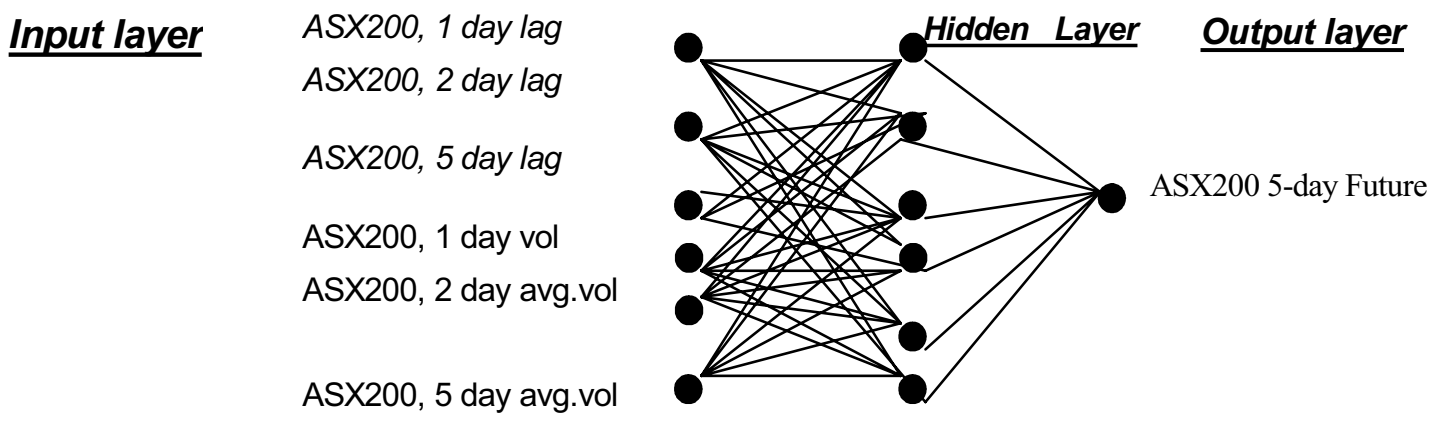

Figure 2. Sample Neural Network for forecasting ASX200 Five-day Future Values

\begin{tabular}{|c|c|c|}
$\begin{array}{c}\text { Jan 3, 2005 to Dec } \\
302005\end{array}$ & Jan 3, 2006 to Jun & July 3, 2006 to Oct \\
& 302006 & 152006 \\
\hline Inputs & Training Data & Predictions
\end{tabular}

Figure 3. Timeline of data used for each market for forecasting five-day future values 